\title{
NACER, CRECER, REPRODUCIRSE Y MORIR ALGUNAS CLAVES ETNOGRÁFICAS DEL CAPITALISMO CONTEMPORÁNEO
} BEING BORN, GROWING UP, REPRODUCING AND DYING SOME ETHNOGRAPHIC KEYS OF THE CONTEMPORARY CAPITALISM

\author{
John Jairo Uribe Sarmiento ${ }^{1}$ \\ Hernán Francisco Bernal Bernal² \\ David Leonardo Quitián Roldán ${ }^{4}$
}

\section{Resumen}

Este artículo presenta los resultados de la investigación Usos y concepciones del tiempo, desarrollada en el grupo de investigación Lúdica, cuerpo y sociedad de la Universidad Pedagógica Nacional. Se discuten los usos y conceptos en torno al ciclo vital a través del capitalismo contemporáneo. También se analizan los vínculos de creación entre la construcción cultural del cuerpo, el yo y el tiempo. Luego, se describe la relación entre el capitalismo y la subjetividad. Finalmente, se desarrolla la proposición del ciclo vital como ciclo de consumo y producción.

Palabras clave: ciclo vital; subjetividad y capitalismo; corporalidad, subjetividad, construcción cultural del tiempo.

Abstract

This paper discusses the uses and concepts around vital cycle through contemporary capitalism. First we analyze the relation between the cultural construction of body, self and time. Next, we describe the relation among capitalism and subjectivity. Finally, we propose vital cycle as a cycle of habits and production..

Keywords: vital cycle; capitalism and subjective; cultural construction of body, the self and the time.

Fecha de recepción: 23 de mayo de 2011

Fecha de aprobación: 21 de septiembre de 2011

1 Antropólogo. Especialista en Planeación y administración del desarrollo regional. Magíster en Ciencia Política. Adelanta estudios en el Doctorado de Estudios políticos y relaciones internacionales. Docente ocasional de la Universidad Pedagógica Nacional. Correo electrónico: juandepatmos1972@yahoo. com.mx; juribe@pedagogica.edu.co

2 Licenciado en educación Física. Magíster en Educación con énfasis en historia de la educación y la pedagogía. Docente de la Universidad Pedagógica Nacional. Correo electrónico: hbernal@pedagogica. edu.co

3 Sociólogo - Magíster en Antropología. Docente ocasional Universidad Pedagógica Nacional. Investigador de la cultura y el deporte. Corresponsal y columnista de Nuevo Estadio. Blogger de El tiempo. Correo electrónico: quitiman@yahoo.es

4 Grupo de investigación - Lúdica, cuerpo y sociedad. Universidad Pedagógica Nacional. Facultad de Educación Física. Bogotá D.C. Colombia 


\section{Presentación}

Nacer, crecer, reproducirse y morir. Ciclo familiar que esconde un modo de articular la vida y el cuerpo al interior los ordenes capitalistas. Se trata de una forma particular de iniciar la vida, de vivirla y de darle final. Estas formas se constituyen en la materia prima de la producción contemporánea: la subjetividad (Guattari y Rolnik, 2006). Las siguientes páginas hacen alusión a uno de los modos como cuerpo, subjetividad y orden capitalista se articulan entre sí, una articulación que podemos denominar biopolítica.

Ahora bien, podría argumentarse que nacer, crecer, reproducirse y morir poco o nada tienen de cultural, que son la simple verificación de un hecho biológico. Esta naturalización del nacimiento, el crecimiento y de los demás momentos refieren precisamente al modo como lo cultural trabaja. Se trata, de una parte, del modo como la vida y el cuerpo entran en relación, una relación de corporalidad en la que se constituye un yo (sobre la relación cuerpo-yo, ver Pedraza, 2007b). En esta relación está en juego, por una parte, el quién, con su fuerza vital, y por la otra, el cuándo y el dónde, con su capacidad para determinar al sujeto, sujeto que puede volver sobre la torsión que lo determina para generar una posibilidad-otra, abierta a nuevos cuándo y dónde (para una discusión sobre la dialéctica del sujeto, ver Badiou, 2009). Este sujeto vive su corporalidad en el nacer, crecer, reproducirse y morir, en un cuándo y dónde capitalista.

En este sentido, vale decir que el plantear el carácter subjetivo y cultural del capitalismo remite a las relaciones sociales de producción que se cristalizan en él. Este tema es recurrente en el marxismo y presenta una serie de retos para los analistas. De un lado, puede caerse en la manida crítica que reduce el marxismo a un mero economicismo, al obviar temas cruciales como la ideología y la alienación, y al centrar la atención en la determinación de la superestructura por la estructura económica. No es éste el lugar de precisar las críticas ni sus limitaciones y posibilidades; sin embargo, debe reconocerse que el propio Marx entendió el desarrollo de las fuerzas productivas como un proceso con implicaciones que podríamos denominar como subjetivas y culturales $^{1}$

1 Laclau y Mouffe (2006), analizan esos supuestos economicismos ortodoxos y colocan en el centro de la discusión lo imaginario, la hegemonía y los efectos de "sutura" subjetiva.
A partir de aquí podemos plantearnos algunas referencias respecto a esa articulación entre economía, cultura y poder. Por ejemplo, para Edgardo Lander, las recetas neoliberales no son tanto una cuestión técnica económica, como una nueva faceta del proceso colonizadorcivilizador, en el cual, la banca multilateral que aplica las medidas de ajuste, hace las veces de la Casa de Indias. Por supuesto, no es nuevo plantear que las energías corporales y subjetivas se encuentran implicadas en la organización económica y social. Sin embargo, el centro de la cuestión se encuentra en el lugar que ocupan esas energías respecto a la producción. Para Guattari y Rolnik, la materia prima del capitalismo, así como de cualquier modo de producción es la subjetividad. Pero esta subjetividad no se restringe a las tendencias o preferencias individuales; está circunscrita a procesos sociales que articulan aparatos infraindividuales y extrapersonales. Es decir, los procesos semióticos, de construcción de sentido, de articulación de un modo de percibir, así como de estructuras cognitivas y afectivas, se juegan en una suerte de micropolítica, de productividad subjetiva. Si bien esta productividad no se centra en una máquina social específica (en una institución privilegiada), ni es producto de la mera individualidad, se trata de los puentes y tensiones que van desde tales máquinas hasta los individuos.

Aquí vale decir que no se requiere sólo lograr una cierta disciplina productiva, sino también generar lo que podríamos denominar como una "disciplina de consumo". Se ha discutido sobre la disciplina productiva ampliamente, entendiéndola a la manera de Foucault (1977), es decir, no tanto como efecto de un poder soberano que actúa censurando, prohibiendo o limitando, sino como poder normalizador, o mejor, como poder subjetivante. Este es el poder que produce referentes efectivos para que cada quien se ubique respecto a las redes sociales de las que participa, pero sobre todo para que se ubique respecto a sí mismo (más adelante se ampliará este aspecto).

El análisis se ha centrado en los dispositivos que se concentran en "producir" trabajadores idóneos. Con todo, vale decir, siguiendo a Santiago Castro-Gómez (2009), que las técnicas de gobierno no se restringen a la producción de comportamientos sobre una cierta población, sino que se requiere lograr que esos comportamientos previamente establecidos sean percibidos como buenos y deseables. De ahí que la publicidad sea entendida por él como una técnica que gobierno que inscribe en el registro de lo deseable un modo de 
referirse al mundo con el que se relaciona. La velocidad y el aprecio por las novedades son, entre otros, elementos de las mentalidades capitalistas que se reprodujeron en Bogotá mucho antes de que se industrializara la ciudad.

Este gobierno de lo deseable es propio del capitalismo, registro de lo que se conoce como biopolítica; hacer vivir y dejar morir es una de sus formulaciones más sintéticas. El hacer vivir biopolítico se refiere, entre otras cosas, a la producción subjetivante de todas y cada una de las esferas vitales. La semiotización de esas esferas vitales en un ciclo imaginario, recurrentemente referido por personas encuestadas en Bogotá, se convierte en un tema de análisis que permite abordar la descripción del carácter capitalista de la construcción de un yo en un proceso de "corporalización". En este sentido, este hacer biopolítico se refiere también al proceso a través del cual se coloca la vida bajo la esfera del poder y, por esta vía, al modo en que influye en el cuerpo. Así pues, la relación de cada quien con su cuerpo es un asunto biopolítico, pues se trata de la forma como ese cuerpo es concebido, cuidado y "jugado" en los terrenos productivos, reproductivos, afectivos y de consumo.

La biopolítica es la experiencia por la cual un hombre o una mujer ajustan sus corporalidades a un cierto tipo imágenes más o menos definidas en modelos corporales asociados al éxito: gimnasio, SPA, cirugía estética, diseño de sonrisa, diseño de imagen, etc. La producción social y subjetiva de la distancia entre el cuerpo heredado y el cuerpo deseado se constituye en un elemento clave de la biopolítica, pues este vacío, enclave del deseo, da lugar a una serie de industrias de bienes y servicios diversos, que se concretan en asesorías psicológicas y médicas para tratar los desórdenes propios de cada caso (vigorexia, anorexia), así como todos los espacios mediáticos que invitan y previenen de los riesgos de este tipo de tratamientos y deseos (Ver Pedraza, 2007a).

Pero tratar al cuerpo como un objeto que se construye en el mercado (como en el caso de las estéticas) y que incluso puede ser vendido en él (como ocurre cuando se aseguran unas piernas, un rostro, etc.) supone un cierto modo de "ubicarse" respecto a sí mismo. Ese cuerpo objeto, del cual cada quien es dueño, supone una relación a través del cual un "yo" usa su cuerpo según le parece y evita que otros lo "usen" sin su consentimiento. Ese yo es una especie de "huésped" que habita temporalmente un cuerpo; se trata del modo como se pone en práctica la separación mente-cuerpo, del cuerpo definido como res extensa, mera "marioneta" que manipula la razón para lograr sus propósitos. En esta estructura, el cuerpo no es sino una máquina silenciosa, incapaz de un deseo propio o de alguna lógica diferente a la que trata la morfofisiología; nada abre la posibilidad de una meditación en la que cada órgano "hable" su propia lengua y viva su propio aprendizaje.

Para desarrollar la discusión que se ha esbozado se referirán algunos aspectos conceptuales referidos al carácter ritual del tiempo, ilustrado con algunos resultados de nuestras investigaciones en Bogotá, cifras sobre las cuales el nacer, crecer, reproducirse y morir, como aspectos claves del ciclo vital, encuentran cierta generalidad. Posteriormente se discutirá el carácter subjetivo y cultural del capitalismo, de modo que se articule una perspectiva sobre el aspecto corporal de la construcción del yo y del modo como la vida, el cuerpo y el poder capitalista se tensionan y reproducen.

\section{El sentido cultural del tiempo: ciclos vitales y recordatorios anuales}

La antropología del tiempo expresa que éste es una construcción cultural, por lo que cada sociedad -en cada época- y, más específicamente, cada sujeto (dependiendo de una larga serie de variables como edad, sexo, religión, clase social, lugar geográfico, formación académica, cultura, etc.) asume y experimenta el tiempo de una forma diferenciadamente propia. De igual manera, la disciplina antropológica acuña la expresión "ritual de paso" para comprender cómo los individuos asumimos nuevos roles sociales cuando los celebramos públicamente. En palabras de Turner (1988), se denomina liminalidad al estado límite -de frontera- que comunica dos situaciones socioculturales: la del estudiante y la del profesional; la del adolescente y el ciudadano (mayor de edad); la del soltero y el casado. El "ritual de paso" sería esa celebración (graduación académica, cumpleaños número dieciocho, matrimonio) que permite dar el paso entre un estado y otro, con la eficacia suficiente para movilizar procesos externos e internos que otorguen al individuo capacidades incluso insospechadas en el escenario previo al festejo. Allí, el sujeto vivencia un espacio-tiempo tripartito: una fase preliminal o previa, una fase intermedia o liminal y otra fase posliminal o posterior. La liminalidad se trata de una manifestación temporal anti-estructura y antijerarquía de la sociedad; de allí su eficacia. Obviamente, como todo ritual, el "ritual de paso" está revestido de elementos mágico-religiosos connaturales a las culturas. 
Las siguientes páginas presentan algunos de los resultados del proyecto de investigación Gestiones del tiempo: concepciones y usos del tiempo en la localidad de Suba, desarrollada con el auspicio del Centro de Investigaciones de la Universidad Pedagógica Nacional en el año de 2008. Se hará mención a algunos datos obtenidos mediante la aplicación de 300 encuestas, que permiten verificar ciertos aspectos de las concepciones y usos del tiempo de los habitantes de la localidad de Suba en Bogota, especialmente personas de estratos medios y bajos. Dichos aspectos fueron contrastados con entrevistas y grupos focales, de modo que la información que se presenta permite hacer generalizaciones sobre la localidad. Sin embargo, estamos convencidos que esta información no sólo habla de esta localidad, sino que puede usarse para plantear reflexiones sobre el cuerpo, la vida y el orden capitalista.

En este sentido, vale la pena iniciar con una discusión sobre la subjetividad y el capitalismo. Víctor Turner (1999) define el ritual como la articulación entre deseo y orden. Se trata de constituir en deseable un orden, de lograr que un orden se constituya en referente subjetivo para quienes lo comparten, es decir, en modos de sentir, percibir y comunicarse. De aquí emerge un conjunto de preguntas relevantes: cómo se subjetiva el orden, cómo se articulan las subjetividades en tensión con el orden social, y si es posible desear otros órdenes posibles y movilizar cambios en él.

La implementación del capitalismo en Colombia se entiende como un proceso de "sujeción", de vinculación de los sujetos a una sociedad de trabajo bajo ideales de "progreso", a las reglas de juego y los estilos de vida capitalistas. Su investigación aborda los modos como los sujetos fueron interpelados en tanto "modernos" y "deseantes", en aplicación de diversas tecnologías de gobierno: "La publicidad es, pues, una tecnología que busca afectar las maneras de sentir con el fin de movilizar maneras de vivir" (2009: 197). Esta movilización de formas de sentir y de percibir se constituye en el desarrollo de procesos sociales subjetivantes y representan cierta articulación entre deseo y orden.

Vale decir que Foucault (1977) desarrolló una analítica del poder que se orientó hacia el abordaje de sus producciones de verdad; el poder produce formas de verdad, es decir, listados de objetos a conocer, preguntas por resolver, estrategias de solución, características de los sujetos implicados en el conocimiento, una cierta relación entre el sujeto y los objetos, un modo de ser sujeto, etc. Pero tales regímenes de verdad producen ciertos efectos en los sujetos, en sus subjetividades, en últimas, en sus formas de percibir, de sentir, de concebir, pero también de desear, de vincularse con el mundo, con los otros ${ }^{2}$. De acuerdo con ésto, se puede plantear que el poder produce efectos subjetivos.

A modo de ejemplo, la biopolítica, entendida como las diferentes formas en las que se articula vida y poder, puede leerse desde la perspectiva que plantea una de las preguntas centrales de la Historia de la Sexualidad (Foucault, 1977). Ésta alude precisamente a la forma en que se constituye el sujeto de deseo que reconoce el sexo como la clave de sí mismo; en otras palabras, la manera como el deseo se constituye en clave para que el sujeto se defina y cómo esta constitución de sujetos deseantes hace parte central de propia constitución del mundo capitalista. Una de las dimensiones de la biopolítica es entonces, el desarrollo de ese gobierno del deseo.

Ahora bien, se encuentra una tensión central como telón de fondo: de un lado, el orden gobierna en la producción de subjetividad, del otro, esos sujetos son partícipes de la construcción de su propio mundo. Si se enfatiza en el gobierno del deseo y en la producción social de la subjetividad, se pierde aquello que es irreductible a lo social, lo irreductible de cada individuo, y éste termina convirtiéndose en un elemento pasivo que se mueve al son de las estructuras o del orden imperante. Si se enfatiza en la individualidad, se pierden los efectos y las operaciones de poder que ocurren en la intimidad de las subjetividades y lo social se reduce a una simple sumatoria de individuos. La pregunta por la articulación entre orden y deseo es entonces una pregunta por los modos como cada sujeto participa en los modos de sujeción propios de juego social, pero también por los modos como se producen movimientos a favor de otros mundos posibles, de deseos propios y singularidades. Como se verá más adelante, las construcciones en torno a los ciclos vitales y a las fechas más importantes de la vida y del año ofrecen procesos de negociación entre los imaginarios y las construcciones identitarias.

Antes de presentar la discusión sobre la subjetividad y el capitalismo propuesto por Guattari y Rolnik (2006), nos detendremos en las fechas ofrecidas por los encuestados como los momentos más importantes del

2 Un análisis de este tipo se puede leer en Castro-Gómez (2009) 
año, de modo que puedan plantearse unos primeros elementos de negociación entre el sujeto y la estructura.

\section{Navidad como meta y año nuevo como partida}

No es de extrañar que la navidad, el mes de diciembre, las vacaciones, los cumpleaños, aniversarios, las muertes de seres queridos y los nacimientos sean las respuestas más repetidas ante las preguntas "¿cuál fue el momento más significativo del año?" y" ¿cuál ha sido el momento más significativo de la vida?". La Navidad o Natividad es la efeméride liminal por excelencia de Occidente: con el nacimiento de Jesucristo se acaba e inicia una nueva era, la señalada en el Nuevo Testamento, que tanto ha influido en nuestra cosmología y cultura. Además del alumbrado o "noche de velitas", el arbolito de navidad, el pesebre, las novenas, los villancicos y los juegos de aguinaldos, hay toda una gastronomía (natilla, buñuelos, uvas, pavo relleno, etc.), una música propia (que arranca en el mes previo con un ya emblemático eslogan radial ${ }^{3}$ que reza: "En noviembre, la música de diciembre") ${ }^{4}$ y un ambiente que alcanza su punto álgido con la Nochebuena. Por ello, varios encuestados (alrededor del 20\%) señalaron el "24 de diciembre" como la fecha de mayor importancia. En el imaginario nacional esta fecha es sinónimo de fiesta y reencuentro con familiares, amigos y seres queridos; así, "el 24" pareciera eclipsar la propia fecha del 25 de diciembre, más apta para el paseo familiar (el "desenguayabe") y para los estrenos cinematográficos de películas nacionales en la cartelera colombiana. Una particularidad de los

3 Colombia es considerado como un país radial por excelencia, en donde se hace y consume radio en cantidad y calidad. "Radio Sutatenza" aún sigue siendo un paradigma mundial de las ondas hertzianas (radio hecha por campesinos para campesinos). Así mismo, es interesante observar como sucesos trascendentes de la política colombiana como El Bogotazo, la Toma del Palacio de Justicia por el M-19 y el reciente fenómeno de los secuestrados por la guerrilla (y todo lo que significa el programa "Voces del secuestro" de Erwin Hoyos) pueden ser explicados desde la radio; máxime cuando ella ha sido protagonista de excepción de esos hechos. La radio como elemento preponderante en el proyecto nacional ha sido tema ampliamente tratado por varios autores como Jesús Martín Barbero, Gabriel Restrepo y María Teresa Lalinde (ver citas a continuación) y como situación de desarrollo específico ver cita de libro de Alape. Un buen ejemplo de ese escenario son las transmisiones deportivas de la segunda mitad del siglo pasado; especialmente del fútbol y la Vuelta a Colombia.

4 Sobre radio, cultura y sociedad, ver Alape (1983), Martín-Barbero (1999), Restrepo (2008) y Lalinde (1996). resultados es que fueron los niños-adolescentes y las mujeres en general (45\% y 42\%, respectivamente), sin distinción de estrato social, los que más eligieron esta época como especial en el desarrollo de sus vidas. Como justificación, los encuestados de entre 10 y 17 años respondieron "regalos/ obsequios" y las mujeres coincidieron en "unión familiar/ reencuentro".

En evidente relación con la Navidad y sus justificaciones (expresadas en las contrapreguntas que indagaban por qué esos momentos eran significativos), aparece el mes de diciembre, que despertó en una franja representativa de los encuestados una suerte de sentimiento apocalíptico (14\% lo dieron como la fecha más importante del pasado año y un 9\% lo calificó como la temporada más significativa de sus vidas); se asume que el año calendario agoniza y por tanto se procede a darle "sepultura".

Invariablemente, los encuestados (especialmente hombres de más de 26 años) respondieron "Diciembre" o "Fin de año" a las preguntas por el momento significativo del año y de la vida. Esto resulta interesante si se cruza con la pregunta que indaga sobre las épocas en que los encuestados dividen su existencia. Allí, la etapa de la escuela, el colegio y la universidad alcanza una presencia del 19\%. Lo significativo es que esos peldaños académicos se compadecen del año calendario: tanto los años escolares como los semestres universitarios están sincronizados con el comienzo, mitad y final de año. Cada año supone un nuevo nivel; así, un 31 de diciembre -con el agüero de la ropa interior amarilla, las doce uvas, las canciones como "Faltan cinco pa' las doce" y "Yo no olvido el año viejo", la quema de los año viejos, los voladores y demás juegos pirotécnicos- supone el éxito ó el fracaso académico. Al respecto, cabe constatar, a manera de ilustración, cómo algunos encuestados, respondieron "Entrega de notas", "Pasar el año", "Recibir el cartón” y "Graduarme con honores" como momentos significativos del año en curso. Como conclusión se podría inferir que la racionalidad implícita en los balances (qué gané y qué perdí) y la ciclotimia como metáfora del destino, alimentan el porcentaje de personas que piensan en diciembre como una fecha que marca su existir.

Vale decir que los cumpleaños ocupan un lugar destacado frente a las fechas más significativas del año. Puede decirse que se trata de la celebración del yo, celebración del nacimiento, o de aquello que da inicio al recorrido vital. Como se verá más adelante, esta fecha marca el momento más importante de la vida para muchos encuestados. 
Tabla 1

\begin{tabular}{|l|c|}
\hline $\begin{array}{c}\text { FECHAS MAS SIGNIFICATIVAS } \\
\text { DEL AÑO }\end{array}$ & $\begin{array}{c}\text { No. de Personas } \\
\text { respondió }\end{array}$ \\
\hline Navidad & 61 \\
\hline Fin de año & 42 \\
\hline Cumpleaños propio y familiar & 68 \\
\hline $\begin{array}{l}\text { Fechas especiales de amor y } \\
\text { amistad }\end{array}$ & 4 \\
\hline Primera Comunión & 4 \\
\hline Día del Padre y de la Madre & 9 \\
\hline $\begin{array}{l}\text { Vacaciones, Semana Santa y } \\
\text { Días de descanso }\end{array}$ & 51 \\
\hline Todos (3) / ninguno (3) & 6 \\
\hline Embarazos y Nacimientos & 11 \\
\hline $\begin{array}{l}\text { Pago de Sueldos o Comienzos } \\
\text { de trabajo }\end{array}$ & 2 \\
\hline Meses diferentes del año & 5 \\
\hline $\begin{array}{l}\text { Ingreso a la Universidad, pro- } \\
\text { moción año escolar }\end{array}$ & 7 \\
\hline Ganar Trofeos y torneos & 23 \\
\hline Muerte de un familiar & 500 \\
\hline No sabe / No responde & 2 \\
\hline Total & 5 \\
\hline
\end{tabular}

Los momentos más significativos del año ponen el acento en la articulación entre el calendario y el tiempo personal, esto es, entre el tiempo estructurado y socialmente regulado, y el tiempo vivido en su intensidad personal. Se trata del tiempo de la vida propia (el cumpleaños) fijado en el canon del calendario, elemento central que "registra" el ingreso de un nuevo individuo a un lugar estatalizado: el registro civil. Queda señalado que la insistencia en la festividad navideña, en tanto ritual, se constituye en otro articulador del orden y el deseo, del cuándo y el dónde que determinan quién se atreve a negociar su lugar en ese mundo.

En las siguientes páginas desarrollaremos algunos aspectos de lo que Guattari y Rolnik (2006) denominan como micropolítica, de los aspectos propios de las relaciones de poder en las relaciones micro-sociales.

Pues bien, Guattari y Rolnik (2006) realizan una cartografía del deseo, discutiendo la constitución de los territorios subjetivos. La primera cuestión que interesa destacar

de este análisis concierne a que tales territorios son producidos socialmente. Eso quiere decir que los modos de percibir, conocer y sentir, son modelados por diversos procesos sociales; es decir, los territorios subjetivos (inconsciente o consciente) cuentan con una suerte de historia que puede leerse según diversas lógicas, entre denominárselas que se encuentran las políticas del deseo.

El análisis de esas micropolíticas, desarrollado por Guattari y Rolnik, se refiere a lo que denominan como orden capitalístico. No se trata del capitalismo en el sentido de un modo de producción económico, sino de las formas como el capitalismo produce subjetividades.

Lo que caracteriza a los modos de producción capitalísticos es que no funcionan únicamente en el registro de los valores de cambio, valores que son del orden del capital, de las semióticas monetarias o de los modos de financiación. Éstos también funcionan de un modo de control de la subjetivación, que yo llamaría "cultura de equivalencia" o "sistemas de equivalencia". Desde este punto de vista, el capital funciona de modo complementario a la cultura en tanto concepto de equivalencia: el capital se ocupa de la sujeción económica y la cultura de la sujeción subjetiva. Y cuando hablo de la sujeción subjetiva no me refiero sólo a la publicidad para la producción Gráfico 1

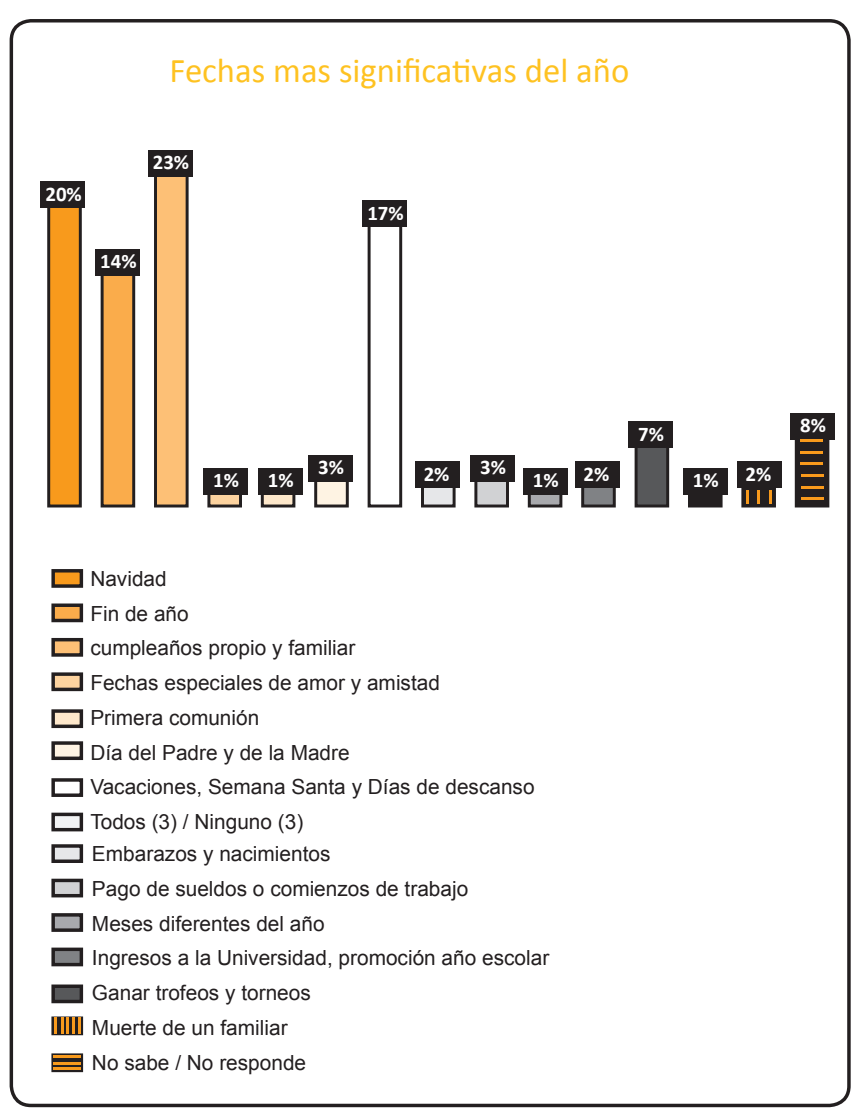


y el consumo de bienes. La propia esencia del lucro capitalista está en que no se reduce al campo de la plusvalía económica: está también en la toma de poder sobre la subjetividad (Guattari y Ronik, 2006: 28).

Desde esta perspectiva, el capitalismo opera como proceso semiótico y de producción de sentido que genera efectos subjetivos. Podría decirse que la toma del poder sobre la subjetividad se basaría en la subjetivación del lucro capitalista, esto es, en construir modos de percepción, modos de sentir y de relacionarse consigo mismo y con los demás que obedecen a la lógica capitalista. Por ejemplo, se tiende a considerar al cuerpo como un objeto de nuestra propiedad; por eso se piensa que se puede hacer con él lo que cada quien quiere y que no puede hacerse nada con el cuerpo de los otros sin su consentimiento. El cuerpo es, entonces, una propiedad privada. De este modo, no sólo se concibe de este modo sino que es-sentido (desde la doble perspectiva de que se le da sentido y es sentido, experimentado). Si esta tendencia es cierta, ese modo de sentirse uno mismo con su cuerpo, no sólo hace eco del orden capitalístico, sino que se constituye en uno de sus pilares.

En otro lugar hemos discutido el carácter de mercancía que adquiere el tiempo cotidiano (Uribe, Quitián y Bernal, 2010). Así, suele decirse que no se tiene "tiempo" cuando no se tiene dinero, mientras que se busca ahorrar dinero ahorrando tiempo, etc. Pero esta subjetivación no es una mera "internalización" del orden social.

Propiamente la cultura de masas produce individuos: individuos normalizados, articulados unos con otros según sistemas jerárquicos, sistemas de valores, sistemas de sumisión; no se trata de sistemas de sumisión visibles y explícitos, como en la etología animal, o como en las sociedades arcaicas o precapitalistas, sino de sistemas de sumisión mucho más disimulados. Y no diría que esos sistemas son "interiorizados" o "internalizados", de acuerdo con una expresión que estuvo muy en boga en cierta época, y que implica una idea de subjetividad como algo dispuesto para ser llenado. Al contrario, lo que hay es simplemente producción de subjetividad" (Guattari y Rolnik, 2006: 28).

Lo anterior quiere decir que la toma del poder sobre la subjetividad que opera el capitalismo, no implica un sujeto preestablecido al que se "engaña" para que asuma un cierto tipo de valores. A la subjetivación como interiorización de un orden objetivo, se opone la idea de la subjetivación como producción social. Ahora bien, dado que la producción de subjetividad se refiere a la semiotización de las realidades sociales, esta construcción de sentido es a su vez construcción de relaciones de fuerza, de sujeciones. De otro lado, la subjetividad se construye en la movilización de terrenos subjetivos, que cuentan con su propia lógica, sus propias racionalidades y formas de acción. Lo que se produce, en este caso, se denomina territorios subjetivos. Pero ¿a qué se refiere con esta denominación? Se trata de los modos como cada uno categoriza o semiotiza su propia experiencia, sus modos de hacer y de proceder. Abordemos un ejemplo: los niños son integrados a un orden en el que construyen una cierta relación consigo mismo, es decir, unos horarios, unas instituciones, unos lenguajes.

"Antes de eso, juegan, articulan relaciones sociales, sueñan, producen pero, tarde o temprano, van a aprender a categorizar esas dimensiones de semiotización en el campo social normalizado. Ahora es hora de jugar, hora de producir para la escuela, ahora es hora de soñar y así sucesivamente" (Guattari y Rolnik, 2006: 31).

El orden capitalístico no opera impregnando una subjetividad predispuesta, una cierta naturaleza humana dada, sino que produce esa subjetividad, al generar modos de semiotizar, esto es, de significar, dar sentido y, en últimas, de establecer relaciones consigo mismo y con los otros. Dichas relaciones pueden ser de sumisión, apegadas a los valores de la acumulación capitalista, asociadas a los ciclos de producción y de consumo, pero también pueden responder a las singularidades de cada quien.

A esta máquina de producción de subjetividad opondría la idea de que es posible desarrollar modos de subjetivación singulares, aquello que podríamos llamar "procesos de singularización": una manera de rechazar todos esos modos de codificación preestablecidos, todos esos modos de control a distancia, rechazarlos para producir modos de sensibilidad, modos de relación con el otro, modos de producción, modos de creatividad que produzcan una subjetividad singular. Una singularización existencial que coincida con un deseo, con un determinado gusto por vivir, con una voluntad de construir el mundo en el que nos encontramos, con la instauración de dispositivos para cambiar 
los tipos de sociedad, los tipos de valores que no son los nuestros" (Guattari y Rolnik, 2006: 29).

Nótese cómo en este apartado se define deseo como una voluntad de vivir según valores propios y de construir el mundo en el que se habita, no como la relación entre pulsiones innatas (vividas por cada individuo, pero comunes a todos) y modos de represión (socialmente organizadas). Los territorios subjetivos, las sensibilidades, se definen también como los modos de ser hombre, de ser mujer, de ser niño, adulto, joven, anciano. Dichos productos no son el mero efecto de una estructura económica, sino la propia materia de la evolución de las fuerzas productivas sociales. En últimas, la producción de subjetividad es la producción de las fuerzas sociales "La producción de subjetividad constituye la materia prima de toda y cualquier producción". (Guattari y Rolnik, 2006: 42)

Todo lo que es producido por la subjetivación capitalística -todo lo que nos llega por el lenguaje, por la familia y por los equipamientos que nos rodean- no es sólo una cuestión de ideas o de significaciones por medio de enunciados significantes. Tampoco se reduce a modelos de identidad o a identificaciones con polos maternos o paternos. Se trata de sistemas de conexión directa entre las grandes máquinas productivas, las grandes máquinas de control social y las instancias psíquicas que definen la manera de percibir el mundo. (Guattari y Rolnik, 2006: 41)

La subversión de la subjetividad dominante se constituye en un objetivo de la propuesta de Guattari y de Rolnik. Esta subversión puede ocurrir en lo micro (en la relación entre unos pocos) o en las grandes máquinas productivas (los medios de comunicación, la publicidad, etc.). Para ello es necesario tener en cuenta que

La subjetividad es producida por agenciamientos de enunciación. Los procesos de subjetivación o individuales (en el funcionamiento de instancias intrapsíquicas, egoicas, microsociales), ni en agentes grupales. Esos procesos son doblemente descentrados. Implican el funcionamiento de máquinas de expresión que pueden ser tanto de naturaleza extrapersonal, extra-individual (sistemas maquínicos, económicos, sociales, tecnológicos, icónicos, ecológicos, etológicos, de medios de comunicación de masas, esto es sistemas que ya

no son inmediatamente antropológicos), como de naturaleza infrahumana, infrapsíquica, infrapersonal (sistemas de percepción, de sensibilidad, de afecto, de deseo, de representación, de imagen, de valor, modos de memorización y de producción de ideas, sistemas de inhibición y de automatismos, sistemas corporales, orgánicos, biológicos, fisiológicos, etc.). (Guattari y Rolnik, 2006: 45)

El análisis de la producción de subjetividad deberá tener en cuenta este doble descentramiento, no en los individuos, ni en agentes colectivos, sino en máquinas extrapersonales e infraindividuales. "Toda la cuestión está en elucidar cómo los agenciamientos de enunciación reales pueden poner en conexión esas diferentes instancias". (Guattari y Rolnik, 2006: 46)

Ahora bien, Guattari y Rolnik distinguen individuo y subjetividad.

Para mí, los individuos son el resultado de una producción en masa. El individuo es serializado, registrado, modelado (...) La subjetividad no es susceptible de totalización o de centralización en el individuo. Una cosa es la individuación del cuerpo. Otra la multiplicidad de los agenciamientos de subjetivación: la subjetividad está esencialmente fabricada y modelada en el registro de lo social. (Guattari y Rolnik, 2006: 46).

El descentramiento de lo subjetivo frente a lo individual se encuentra acompañado de su fragmentación; se desarticula, el ideal de un individuo moderno que se caracteriza por su conciencia y su coherencia. Muchos actos cotidianos se desarrollan sin que intervenga la conciencia: conducir, caminar, montar bicicleta, son actos mecánicos, de modo que el individuo no se constituye en una unidad autónoma, regida por la razón. Ahora bien, en los agenciamientos subjetivos se pone en juego al individuo:

El lucro capitalista es, fundamentalmente, producción de poder subjetivo. Eso no implica una visión idealista de la realidad social: la subjetividad no se sitúa en el campo individual, su campo es el de todos los procesos de producción social y material. Lo que se podría decir, usando el lenguaje de la informática, es que, evidentemente, un individuo siempre existe, pero sólo en tanto terminal; esa terminal individual se encuentra en posición de consumidor de subjetividad. Consume sistemas de representación, de 
sensibilidad, etc., que no tienen nada que ver con categorías naturales universales. (Guattari y Rolnik, 2006: 47)

Con todo, este consumo de subjetividad que realiza el individuo no es absolutamente pasivo. Guattari y Rolnik se apoyan en una metáfora lingüística para explicar dicho carácter:

Existe el lenguaje como hecho social y existe el individuo hablante. Lo mismo ocurre con los hechos de subjetividad. La subjetividad está en circulación en grupos sociales de diferentes tamaños: es esencialmente social, asumida y vivida por individuos en sus existencias particulares. El modo por el cual los individuos viven esa subjetividad oscila entre dos extremos: una relación de alienación y opresión, en la cual el individuo se somete a la subjetividad tal como la recibe, o una relación de expresión y de creación, en la cual el individuo se reapropia de los componentes de la subjetividad, produciendo un proceso que yo llamaría de singularización. (Guattari y Rolnik, 2006: 48)

Esta perspectiva ubica la subjetividad en diversos ámbitos, no sólo en una cierta economía afectiva doméstica, sino en escenarios tan heterogéneos como las industrias biológicas y genéticas (vacunas, productos inmunológicos, entre otros). Ese individuo oscila entre la alienación y la singularización, en la encrucijada de diversos componentes de subjetividad. Si, por una parte, el individuo es una terminal que consume procesos subjetivos que ocurren en la articulación de dinámicas infrasubjetivas y extrapersonales, por otra, ese individuo puede participar en la creación y circulación de otras subjetividades, si vivencia su proceso de subjetivación como singularizante.

Para finalizar esta sección, es importante señalar que la culpabilización y la infantilización se constituyen en dos de los mecanismos claves de la subjetivación capitalística. La primera se refiere al modo como los individuos se relacionan con los modelos ofrecidos por este tipo de sociedad. Se trata de modelos de comportamiento que, al no ser reproducidos "eficientemente" por los individuos, son experimentados con culpa: no hacer, no tener, no ajustarse a cierto estilo, se constituye en origen de un sentimiento de culpa, sensación que obliga al sujeto a buscar formas de adaptación, al punto que puede renunciar a cuestionar los modelos imperantes, a renunciar a la creación de deseos propios.
La infantilización se refiere al mecanismo a través del cual los individuos evitan pensar por sí mismos. Esos modelos, lo que podríamos denominar como su institucionalización, en el universo capitalístico, se constituyen de tal modo que los individuos pueden encontrarse alienados de su propio pensar.

Los procesos subjetivantes, tanto extra-personales como Infra-individuales, plantean un conjunto de elementos claves para el análisis de la ocupación como proceso de producción de sentido: en el plano micro-político, la ciencia ocupacional puede promover procesos singularizantes, formas de ser, de hacer y de llegar a ser, que contribuyan a la superación de los mecanismos de culpa y de infantilización. Para ello debe investigar los modos como se definen y desarrollan los modelos de comportamiento, su posible articulación con los individuos y las posibilidades de movilización de otras sensibilidades.

Así que la semiotización del tiempo, según se ha podido sugerir ya, se constituye en uno de esos mecanismos de articulación entre lo infrapersonal y lo extraindividual, un modo de gobierno del deseo, materia prima de la expansión capitalista. Pero esta materia prima se articula en lo que podríamos llamar como la corporalización del yo, esto es, la extensión de un yo a través de la vida, vida de la que cada quien tiene noticia a través de su cuerpo. Para introducir este análisis vale la pena detenerse en el análisis de los momentos más significativos para los encuestados.

Años que se recuerdan, que se cumplen y que se niegan

Si el recordatorio del nacimiento de El Mesías fue notablemente elegido por los encuestados (20\% lo calificó como lo más significativo del año y casi un 10\% lo consideró como lo más significativo de la vida), fue el propio nacimiento y el de los seres queridos (como abuelitos, padres, parejas, hijos, hermanos y sobrinos) el más señalado como significativo del año y el más importante de sus vidas (de hecho, para un 56\% del número de personas que escogieron la categoría "cumpleaños", el día de su nacimiento -varios enunciaron la fecha exacta- es lo más importante de su vida). Otra vez la metáfora del ciclo aparece, coincide y se contrapone al "rito de iniciación" (o de re-iniciación) que supone un aniversario más de vida y el "ritual de paso" en fechas decisivas como los "15 años" para las mujeres y los "18 años" para los varones. Sobre el particular es bueno 
mostrar cómo para el 19\% de las mujeres "su fiesta de quince" y para el $8 \%$ de los hombres "cumplir 18" son momentos indelebles en su memoria. Esto no es gratuito, pues esas celebraciones son las que permiten o dan entrada al "mundo de los adultos" que significa, entre otras, que con esas calendas ganan ciertas libertades, como "tener novio", tal como respondió una entrevistada (al menos, ya pueden presentarlo en sociedad) y que ellos "pueden mandarse solos" como contestó un encuestado.

Es llamativo que las integrantes de ese 19\% de mujeres que escogieron "la fiesta de quince" son menores de 26 años (pero de todas las clases sociales); de ahí en adelante categorías como "embarazo", "matrimonio", “conocer pareja" o "muerte de ser querido" aparecen con mayor frecuencia. La distinción que introduce Castells (1998) entre identidad y rol, puede ser útil aquí. Uno de los elementos centrales del análisis de Castells sobre son más fuertes que los roles. Las primeras organizan el sentido, definido como la identificación simbólica del objetivo de su acción, mientras que los segundos organizan las funciones. En la sociedad en red -la sociedad contemporánea $^{5}$ - los individuos organizan el sentido en torno a una identidad primaria de la cual emanan otras, ésta se mantiene en el tiempo y el espacio. La cuestión entonces es establecer cómo, desde dónde, por quién y para quién se construyen las identidades.

Se puede plantear que cada etapa de la vida está marcada por momentos especiales y únicos que se van volviendo prioritarios para el recuerdo (memoria inmediata); el sentido de la vida está en relación con la tensión entre el rol social y la identidad, específicamente en las negociaciones de los individuos frente a las asignaciones. Por ello, la fiesta de quince años, con la importancia que pudo tener, no está en capacidad de superar la impronta espi-

Gráfico 2

Momento significativo de la vida

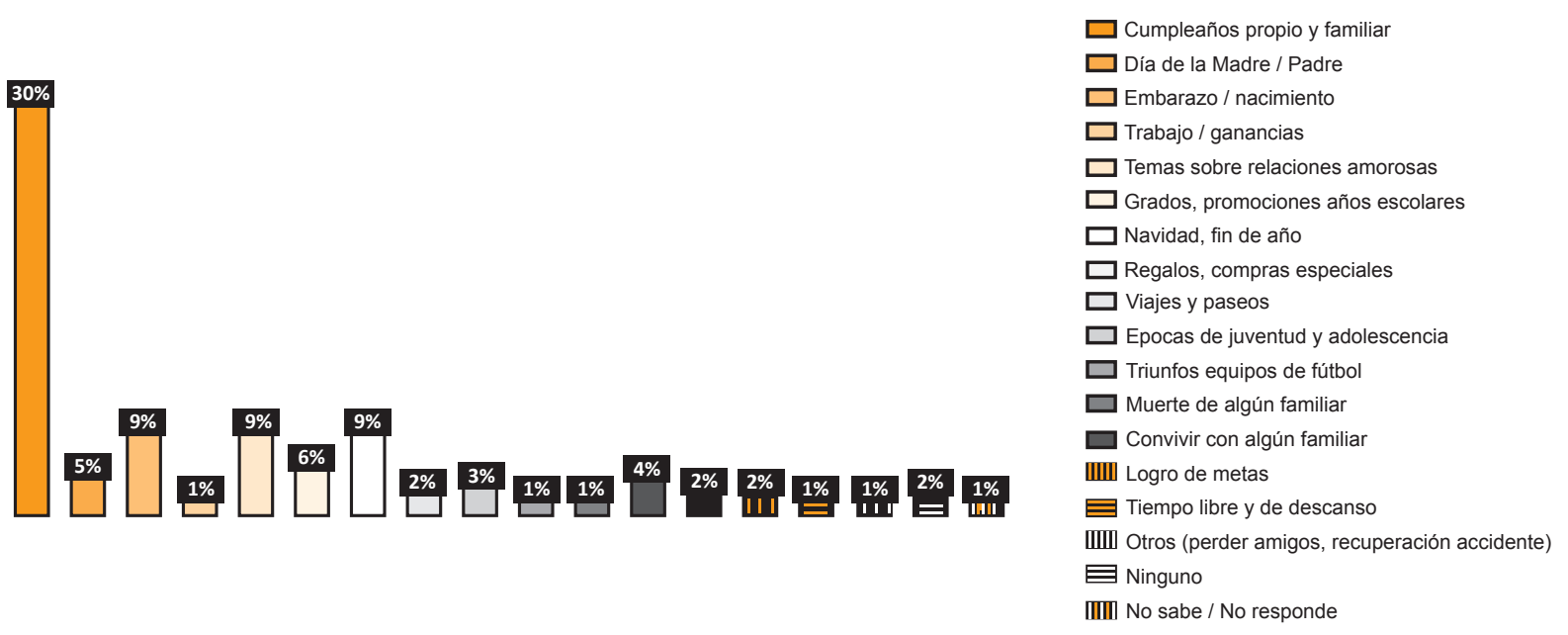

los movimientos sociales es precisamente la identidad. Ella se constituye en fuente de sentido y experiencia, de la construcción de sentido en atención a elementos culturales. Puede existir pluralidad de identidades en un individuo. Ahora bien, las identidades se distinguen de los roles, en la medida en la que estos son asignados y definidos socialmente, mientras, las identidades son construidas por los propios individuos. En este escenario los individuos puede negociar sus identidades con las instituciones que generan los roles. En todo caso, desde la perspectiva de los individuos, las identidades

5 La sociedad red difiere de las sociedades tardo-modernas. En estas últimas, el "yo" se construye reflexivamente, en el proceso de comprensión de lo que se hace y del por qué se hace: "el ascenso de la sociedad red pone en tela de juicio los procesos de construcción de la identidad durante ese periodo (tardo-moderno), con lo que induce nuevas formas de cambio social. Ello se debe a que la sociedad red se basa en la disyunción sistémica de lo local y lo global para la mayoría de los individuos y grupos sociales. Y, añadiría, por la separación en diferentes marcos temporales del poder y de la experiencia" (Castells, 1998: 33). De este modo, la reflexividad se hace inalcanzable para la mayoría. 
ritual (y la evocación del recuerdo) del matrimonio, el divorcio, el viaje al exterior ó el nacimiento de un hijo.

Un rasgo significativo de la encuesta es que con el aumento de los años, en las mujeres desaparece progresivamente la respuesta "cumplir años". Cuando la mencionan, lo hacen en relación con un ser querido (especialmente padres e hijos). Esta desaparición del cumpleaños y las fiestas de quince años, en favor del matrimonio y de los hijos, se articula a la gestión de la vida en relación con los roles y etapas culturalmente elaborados. Cada edad cuenta con asignaciones de rol, que son asumidas por los encuestados en la medida en que los momentos significativos para sus vidas se vinculan con los momentos de un ciclo vital establecido en el imaginario ${ }^{6}$. No obstante, estas fechas importantes, que coinciden con los roles del ciclo vital, son procesadas y elaboradas a partir de significados personales que evidencian la relación del yo con la existencia, en otras palabras, el despliegue de la corporalidad, concepto que se ampliará más adelante.

Respecto al "olvido" de los cumpleaños para las mujeres mayores, no se puede inferir que festejar una vuelta más de almanaque ${ }^{7}$ haya dejado de ser un hecho gratificante: no poseemos datos que nos ayuden a ratificar o descartar esa opción. Queda por establecer si las épocas que conforman el ciclo vital condicionan de tal forma, al punto de pronosticar que las adolescentes y jóvenes de hoy, verán con poco entusiasmo sus cumpleaños en unos años; tampoco sabemos si las mujeres adultas de hoy celebraron con igual alegría sus fiestas de quince años.

Sin querer validar estereotipos sexistas, cabe anotar que, al igual que "la fiesta de 15", "mi primer beso" fue

6 Se emplea el término imaginario en el sentido de Laclau y Mouffe (2006), es decir, entendida como una sutura simbólica que ayuda a construir un sentido de coherencia y totalidad para los sujetos que enfrentan las múltiples fracturas que los atraviesan.

7 "Toda broma encarna una realidad que se pretende ocultar" es la reflexión vertida por Freud (1986) para desentrañar el sentido social del chiste. Pues bien, aquel gracejo de que "la mujer nunca cumple más de 25 años" y aquella creencia popular de que es un acto de mala educación "preguntarle la edad a una dama" (contemplada en el Manual de Urbanidad de Carreño, 1856), son insumos que contribuyen al debate teórico que busca comprender cómo existe una suerte de control social que condiciona la manera de asumir el paso de los años y la estética, al tiempo que desdibuja conceptos como el de la "sabiduría que da el paso de los años" y la longevidad. una respuesta que surgió para un importante grupo de mujeres menores de 26 años (11\%), mientras que la respuesta "tener mi primera relación sexual" fue aludida por $8 \%$ de los jóvenes varones que atendieron la encuesta.

Por el contrario, para los varones interrogados, el cumplir años es un acto satisfactorio y gratificante en

\begin{tabular}{|l|c|}
\hline $\begin{array}{l}\text { MOMENTO SIGNIFICATIVO DE } \\
\text { LA VIDA }\end{array}$ & $\begin{array}{c}\text { No. de Personas } \\
\text { respondieron }\end{array}$ \\
\hline Cumpleaños propio y familiar & 89 \\
\hline Día de la Madre / Padre & 15 \\
\hline Embarazo / nacimiento & 28 \\
\hline Trabajo / ganancias & 3 \\
\hline $\begin{array}{l}\text { Temas sobre relaciones amo- } \\
\text { rosas }\end{array}$ & 26 \\
\hline $\begin{array}{l}\text { Grados, promociones años } \\
\text { escolares }\end{array}$ & 17 \\
\hline Navidad, fin de año & 28 \\
\hline Regalos, compras especiales & 5 \\
\hline Viajes y paseos & 9 \\
\hline $\begin{array}{l}\text { Epocas de juventud y adoles- } \\
\text { cencia }\end{array}$ & 4 \\
\hline Triunfos equipos de fútbol & 3 \\
\hline Muerte de algún familiar & 12 \\
\hline Convivir con algún familiar & 6 \\
\hline Logros de Metas & 2 \\
\hline Tiempo libre y de descanso & 2 \\
\hline Otros (perder amigos, recuper- & 300 \\
\hline Ninguno & 5 \\
\hline No sabe / No responde & 2 \\
\hline Total & \\
\hline
\end{tabular}

todas las edades, lo que parece hacer eco de la creencia, socialmente difundida, de que los años "hacen más interesantes a los hombres"8 que es subsidiaria de la máxima de Carreño de "la edad, dignidad y gobierno". Esto se evidencia en el hecho de que el 8\% de los hombres encuestados, de todas las clases sociales y todos los rangos de edad, señalaron la mayoría de edad como decisiva en sus vidas.

8 Entre más ganas, más canas es otra de las frases que hacen carrera a la hora de aludir el tema de la edad en los hombres. 
Aquí empiezan a dibujarse algunos aspectos claves de la corporalidad y del vínculo entre el yo y la vida.

Si la extensión de la vida sólo es posible en y a través del cuerpo, debe insistirse en que esta extensión se vincula a los modos en que la vida se define en periodos que dan cierta coherencia imaginaria a su transcurrir. Esta coherencia se encuentra en la encrucijada de la significación de estos periodos en virtud de la negociación que ocurre entre los roles y las identidades. Ahora bien, los momentos más significativos del año y de la vida, en referencia a los ciclos vitales establecidos con los encuestados (que analizamos más adelante), aluden a un modo particular de relacionar el cuerpo y la vida. Una forma simplificada de referir esta relación se funda en el hecho de que el "yo", "habita" al cuerpo. No es que el "yo" se constituya por el cuerpo, sino que ese "yo" vive a través de un cuerpo del cual es poseedor.

En este sentido, vale la pena detenerse en la discusión que desarrolla Planella (2006) respecto a lo que denomina cuerpo-objeto y cuerpo-sujeto. Para este autor, el dualismo alma-cuerpo se articula a la cosificación del cuerpo y a la separación cuerpo-persona.

Así mismo, considera necesario proponer una pedagogía que supere estos dualismos que han marcado la historia occidental. Siguiendo a Le Breton, plantea que el cuerpo de la modernidad se ha separado del hombre, y ha producido una separación de éste con los otros y con el cosmos. Para él, Descartes profundiza la escisión cuerpo-alma que se había propagado desde la Edad Media en tanto que entiende que el cuerpo es "figura" que recibe el movimiento de algún factor externo: "Dicho con otras palabras, el cuerpo será denominado Res extensa y el alma Res cogitans. La Res extensa se referirá a la parte corpórea y es concebida como puro mecanismo, ya que es algo que tengo delante de mi y que es sensible" (Planella, 2006: 72). Desde esta perspectiva, el pensamiento resulta externo al cuerpo.

A partir de esta dualidad, Descartes fundamenta su formulación Cogito, ergo sum.

Con las aportaciones anatómicas y las filosóficas el cuerpo se convierte en algo axiológicamente extraño al hombre. Esta axiología prima al individuo frente a la colectividad, con lo cual se refuerza esta necesidad de marcar bien las fronteras entre yo y los otros. En este sentido se debe tener en cuenta la lectura que del cuerpo se hace en la modernidad que lo sitúa como la parte menos humana del hombre, más próximo a su condición de animalidad. (Planella, 2006: 73)

La corporalidad de la modernidad separará al hombre de su animalidad, es decir, ha sido rebajada como condición para "hacerlo" más humano. En este contexto será posible pensar el cuerpo como una máquina, aspecto degradado de la persona, al punto que termina contraponiéndose cuerpo y persona.

El cuerpo objeto, tratado como una cosa, es también objetivo de control: la higiene corporal es regulación social, constitución de cuerpos dóciles, pero también constitución de clases peligrosas a ser excluidas. En ese cuerpo-cosa se inscribe el orden, el cual aplica estrategias para controlarlo cuando ha producido desórdenes. Como plantea Planella, en el siglo XIX,

Si por un lado la higiene corporal es sinónimo de rectitud moral, la suciedad corporal nos indica que aquel cuerpo pertenece a alguien de la clase trabajadora o de la clase peligrosa. Esta asimilación de las clases a través de las estéticas y presencias corporales hará que se asimile la clase peligrosa a la clase trabajadora. El cuerpo higiénico y victoriano se balancea entre las posibilidades que los avances médicos y biológicos le ofrecen, y el control teológico sobre sus actos y pensamientos corporales (Planella, 2006: 77).

Como se discutirá a propósito de la pregunta por las etapas vividas por los encuestados, esta disposición del cuerpo-objeto, habitado por un yo, res cogitans propia de la modernidad, éste se constituye en un aspecto relevante de la contemporaneidad capitalista, esto es, del mecanismo inmunitario de la modernidad.

\section{El camino de la vida y los textos de biología de Henao y Arrubla}

En el 2007, la canción “El camino de la vida” de Héctor Ochoa fue seleccionada por los oyentes de las emisoras de RCN, como la canción colombiana del siglo XX. En su letra, la canción andina hace un recorrido por las etapas aparentemente emblemáticas del ser humano: infancia, adolescencia, juventud y adultez entendida como constitución de una familia y la senectud.

De prisa como el viento van pasando

los días y las noches de la infancia,

un ángel nos depara sus cuidados, 
mientras sus manos tejen las distancias.

Después llegan los años juveniles,

los juegos, los amigos, el colegio,

el alma ya define sus perfiles,

y empieza el corazón de pronto a cultivar un sueño.

Y brotan como un manantial las mieles del primer amor, el alma ya quiere volar, y vuela tras una ilusión,

y aprendemos que el dolor y la alegría

son la esencia permanente de la vida.

Más luego cuando somos dos, luchando por un ideal,

formamos un nido de amor, refugio que se llama hogar,

y empezamos otra etapa del camino:

un hombre, una mujer, unidos por la fe y la esperanza.

Los frutos de la unión que Dios bendijo,

alegran el hogar con su presencia,

a quién se quiere más, sino a los hijos,

son la prolongación de la existencia.

Después cuántos esfuerzos y desvelos,

para que no les falte nunca nada,

para que cuando crezcan lleguen lejos

y puedan alcanzar esa felicidad tan anhelada.

Y luego cuando ellos se van, algunos sin decir adiós, el frío de la soledad, golpea nuestro corazón.

Es por eso amor mío que te pido: por una y otra vez si llego a la vejez que estés conmigo.

El contenido de la tonada de cuerdas coincide grosso modo con el dictamen memorístico (y nemotécnico) de los textos escolares de biología del siglo pasado (especialmente hasta la década del 80), que comparten con la Historia de Henao y Arrubla (1911) el elemento memorístico, pues sostienen que "Los seres vivos nacen, crecen, se reproducen y mueren" (s.p.). Esto quiere decir que forzosamente, como en el fatalismo del mundo griego, toda la especie humana está destinada a satisfacer esas etapas de la vida. Del universo de 300 encuestados, un 92\% de los consultados establecieron el modelo "infancia- juventud- adultez" con variaciones como "niñez- adolescencia- conocer pareja/ matrimonio" o "infancia- juventud ser padre/madre".

No obstante, muchas de esas etapas están divididas por celebraciones religiosas como "el bautizo", "la primera comunión", "el matrimonio"; ceremonias y compromisos sociales como "el grado de bachillerato o la universidad", "la fiesta de quince", o "la prestación del servicio militar"; actos emancipatorios como "la primera excursión fuera de la ciudad o al exterior", "el primer campamento", "el primer trabajo" (la primera quincena), "salirme de la casa para vivir solo/a"; fechas personales como "mi primera asistencia al estadio", "un accidente" o "mi primera relación sexual" o even- tos naturales como el "nacimiento de un hermano" o "la muerte de la madre" u otro ser querido.

Finalmente, está el hecho de la ausencia temporal o definitiva de un ser querido. La muerte está presente Tabla 3

\begin{tabular}{|l|c|}
\hline \multicolumn{1}{|c|}{ ETAPAS QUE HA VIVIDO } & $\begin{array}{c}\text { Personas que } \\
\text { respondieron }\end{array}$ \\
\hline Niñez / Infancia & 124 \\
\hline Epoca del colegio & 43 \\
\hline Escuela & 10 \\
\hline La Universidad & 6 \\
\hline Adolescencia & 12 \\
\hline Juventud & 5 \\
\hline Muerte de familiares & 7 \\
\hline $\begin{array}{l}\text { Tener o terminar una relación, } \\
\text { formar hogar }\end{array}$ & 10 \\
\hline Vivir con Mamá & 2 \\
\hline $\begin{array}{l}\text { Otras celebraciones (bautizo, } \\
\text { quince años, etc.) }\end{array}$ & 3 \\
\hline $\begin{array}{l}\text { Otras (jugar fútbol, recuerdo de } \\
\text { una caida, etc.) }\end{array}$ & 4 \\
\hline No sabe / No responde & 74 \\
\hline Total & $\mathbf{3 0 0}$ \\
\hline
\end{tabular}

en un porcentaje significativo de los entrevistados: cerca del 6\% afirmó que en el año en curso y en su vida, en general, la pérdida de la madre, el padre, los abuelos, tíos, hermanos u otro familiar son mojones imborrables en su memoria y marcaron etapas de su vida. Se incluye en este ítem "la muerte simbólica", resaltada en eventos como las rupturas sentimentales (separaciones y/o divorcio), la pérdida de amigos por dejar escenarios como la escuela, el colegio ó la universidad y los viajes que los han alejado física y temporalmente.

Con estas variaciones, nacer, crecer, reproducirse y morir, se constituye en un referente para la identificación de las etapas vitales, identificación que da lugar a la relación del tiempo, del transcurrir, con la construcción de un yo que se "negocia" entre las determinaciones (el cuándo y el dónde) del rol y las creaciones identitarias (las construcciones del quién). El cuerpo como objeto y el tiempo como mercancía, se encuentran en la encrucijada de un yo. Se nace para crecer y se crece como ejercicio del consumo: los hijos cuidados por un ángel, los amigos, el colegio y en el corazón brotan las mieles del primer amor; es el momento de la familia, 
de la reproducción y de la producción, para finalmente volver a la vejez, etapa de un nuevo consumo.

Con estas aclaraciones, el ciclo vital celebrado por "El camino de la vida" consiste en registrarse en el inicio de la vida (nacer), consumir, nutrirse de su familia (crecer), consumir y producir, iniciando y proveyendo una nueva familia (reproducirse) y consumir (envejecer) hasta morir.

Es clave insistir que este ciclo de consumo-producciónnacimiento-crecimiento-reproducción-y-muerte sólo es posible si el cuerpo se vive como un objeto y si el tiempo se comercia, esto es, si se entiende como una mercancía.

\section{Referencias}

Agamben, G. (2004). Estado de excepción. Homo sacer II, 1. Valencia: Pre-textos.

Agamben, G. (2006). Homo sacer. El poder soberano y la nuda vida. Homo sacer II, 1. Valencia: Pre-textos.

Alape, A. (1983) El Bogotazo: memorias del olvido. Bogotá: Planeta

Bauman, Z. (2007). Tiempos líquidos. Barcelona: Tusquets.

Cadena, A. (2004). Proyectos sociopolíticos, poblacionales y familias: de las políticas de higiene al control a través del afecto. Colombia 1900-1999. Bogota: Documentos CESO No. 76. Centro de Estudios Socioculturales e internacionales CESO. Universidad de los Andes.

Carreño, M. (1856) Manual de urbanidad y de buenas maneras. Nueva York: D. Appleton y C.

Castells, M. (1998) La era de la información. Vol. 2 El Poder de la identidad. Madrid: Alianza

Escobar, A. (1998). La invención del tercer mundo. Bogotá: Norma.

Esposito, R. (2006). Bíos. Biopolítica y filosofía. Buenos Aires: Amorrortu.

Foucault, M. (1977) Historia de la Sexualidad. 1. La Voluntad de Saber, México: Siglo XXI. (2000). Defender la sociedad. Buenos Aires: Fondo de Cultura Económica. (1999). El orden del discurso. Barcelona: Tusquets.

(1999a). Historia de la Sexualidad II. México: Siglo XXI.

(2006). La hermenéutica del sujeto. México: Fondo de Cultura Económica.

(2007). El Nacimiento de la Biopolítica. Buenos Aires: Fondo de Cultura Económica.
Gráfica 3

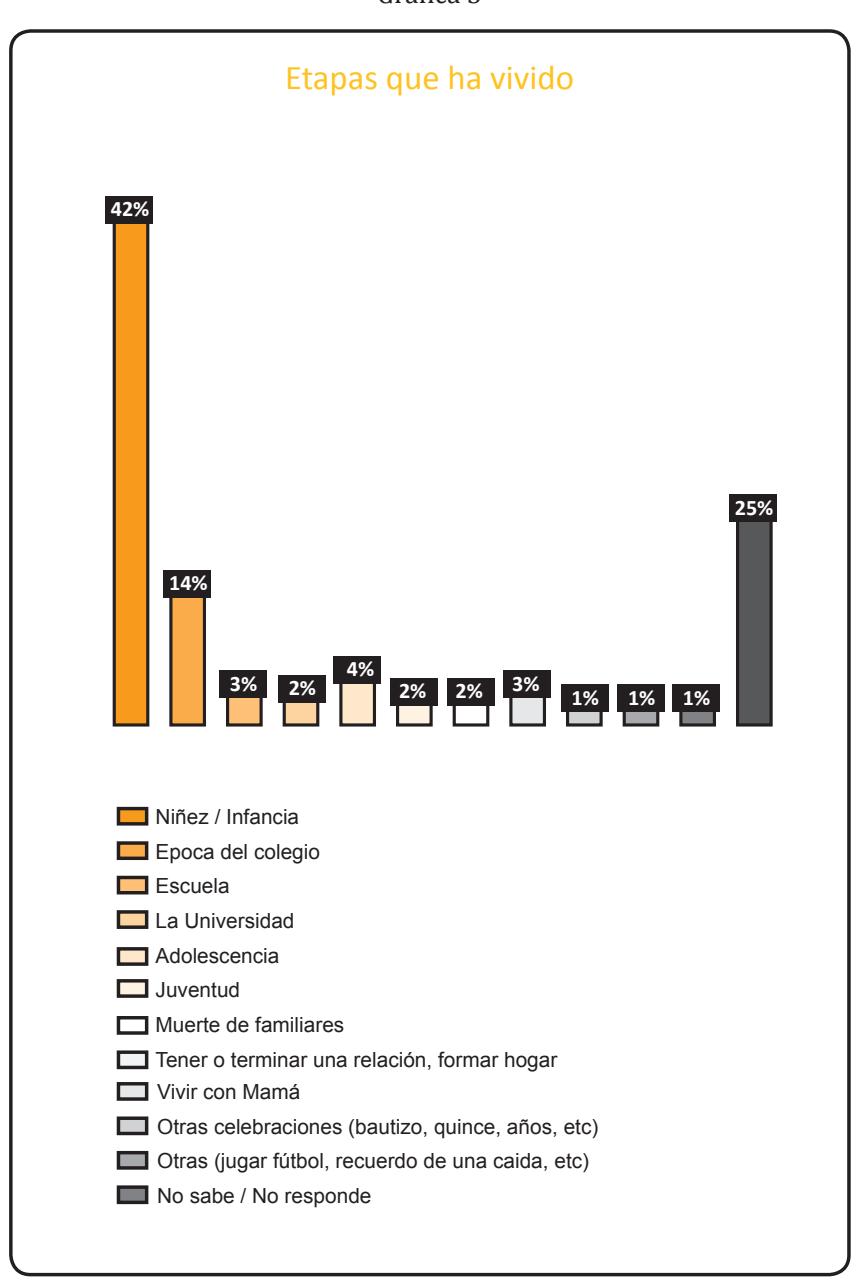

Hart, M. y Negri, A. (2004). Multitud. Guerra y democracia en la era del Imperio. Barcelona: DEBATE-MONDADORI.

Henao, J. Y Arrubla, G. (1911). Historia de Colombia para la enseñanza secundaria. Bogotá: Academia Colombiana de Historia.

Laclau, E. Y Mouffe, C. (2006). Hegemonía y estrategia socialista. Buenos Aires: Fondo de Cultura Económica

Lalinde M. (1996). El desarrollo radial en Colombia. En: Historia Crítica. No. 28. Bogotá: Universidad de los Andes.

Martin-Barbero, J. (1999) Los ejercicios del ver. Hegemonía audiovisual y ficción televisiva. Barcelona: Gedisa

Perea, C. (2006). ¿Qué nos une? Jóvenes, cultura y ciudadanía. Bogotá: La Carreta Social y Universidad Nacional.

Pedraza, Z. (2007a). "Introducción. Políticas y estéticas del cuerpo: la modernidad en América Latina". En: Zandra Pedraza Compiladora. Políticas y estéticas del cuerpo en América Latina. Bogotá: Universidad de los Andes

(2007b). “Dejar nacer y querer vivir: gestión y 
gestación del cuerpo y de la vida". En: Zandra Pedraza Compiladora. Políticas y estéticas del cuerpo en América Latina. Bogotá: Universidad de los Andes

Planella, J. (2006). Cuerpo, cultura y educación. Bilbao: Desclée de Brouwer.

Restrepo, G. (2008) Programa de Comunicación y Sociedad (IECO, texto inédito)

Turner, V. (1999). La selva de los símbolos. Madrid. Siglo XXI.

(1988). El proceso del ritual. Madrid: Taurus.

Uribe, J. (2007) “Corporalidad juvenil: retos para la educación en salud". Revista Pedagogía y Saberes. No. 27.

(2001). La Invención de lo Juvenil. Bogotá: Programa Desarrollo Institucional y comunitario, Programa de Cooperación Internacional Unión Europea - República de Colombia.

(2008). "Cuerpos del trabajo: concepciones del cuerpo". Ponencia presentada en el Segundo Encuentro Internacional sobre estudios de Fiesta, Nación y Cultura. Panel Ocio, Recreación y Deporte. Bogotá.

Uribe, J., Quitián, D. Y Bernal, F. (2010). “El juego como resistencia: el juego frente al tiempo de la alineación". En: Revista Pedagogía y Saberes No. 31

Virno, P. (2003). Gramática de la multitud. Buenos aires: Colihue. 